\title{
The Effects of Psychological Schema in Communication Behaviors
}

\author{
SU Ping \\ Qingdao University of Science and Technology, Qingdao, China
}

\begin{abstract}
This study investigates the influence of psychological schema and communication behaviors in communication. Just as different disciplines and theorists use different concepts for different purposes, individuals may have different mental patterns of communication depending on their experience. The effects of different psychological behaviors can differ dramatically. The process of culture acquisition and communication is extremely a complex psychological process. Psychological schema determines how communicators analyze other people's information and respond with their own judgment about the speakers' cultural perspectives. The negative effect of the anomalous individual psychological element is fundamentally a mental process. It has a deep impact on people's communicative behaviors.
\end{abstract}

Keywords: psychological schema, intercultural communication, behaviors, cultural perspectives

\section{Introduction}

Nowadays, there are a growing number of people who live abroad and speak another language every day. For one reason or another, people have to speak another language in their daily life. The communication between people happens not only in their own culture but also cross cultures. The paper starts with a brief discussion of the basic psychological schema concerning communication. When we examine the nature of our communication from the view of psychology, we can easily see that our psychological schema play a very important role in our communication behaviors.

The negative effect of the anomalous individual psychological element is fundamentally a mental process. Conformity behavior and anxiety in communication is much higher than that of other subjects. Psycholinguistics believes the process of language acquisition is extremely a complex psychological process. Studying personal psychological factors and analyzing the impacts help us understand individual psychological element and mental process in which language users have encountered.

\section{Language and Communication Strategies}

Language is the media of our culture; in November 1999, UNESCO (United Nations Educational Scientific and Cultural Organization) announced that February 21 is International Mother Language Day, which is designed to promote the diversity of languages and cultures. Psychological factors have dynamic, complex, and ever-changing effects on learning. On one hand, language is an important part of our culture and on the other hand, language is a carrier of culture. Some specialists have calculated that languages are disappearing

SU Ping, associate professor, English Department, Qingdao University of Science and Technology. 
twice as fast as the number of mammals becoming extinct and four times the amount of birds. It is estimated that there are approximately 5,000-6,000 languages existing in the world and half of them will vanish during the 21 st century. Worse yet, 80 percent of them may disappear in the next 200 years. Our communication competence is based on our language and cultural perspectives. To enhance human communication, we must promote the diversity of languages and cultures. When we communicate, we consciously and unconsciously adjust our psychological schema to finish the communication. Our psychological schema is influenced by our cultural perspectives which exist in our decision of communicative language and strategies.

The consequences of our language and communication strategies are not immediate but should be after a period of time after the resonance gradually emerging. The consequence is more obvious in intercultural communication in which people have to communicate with a foreign language. Maybe it is for survival or for their work that people are required to speak another language. People have a special psychological schema when a different language or culture is involved. In the process of learning foreign languages, there are inevitably some personal psychological factors. So how do they feel about it? Studying the psychological process of their second language experience may help understand them better. Fully mobilizing their internal factors and taking their advantages to achieve the perfect combination of their second language and their cultures erode their love towards their native tongue according to the author's interview on some foreigners in her local area.

\section{Psychological Schema in Communication}

In communication, people's psychological schema is changing. For example, we learn we do not need to make excuses to everyone for every little mistake we make in our communication although sometimes we know we are accountable to ourselves. We also learn we are allowed to change our minds and we do not need to feel bad about it. We take the blame for things we have no control of. In fact, we learn some things that we should not deal with at all. For example, if our parents are separated, we slowly learn we cannot and we should not deal with it. This psychological schema helps us to face the situation with a sensible point of view. We do not have to know everything in communication. We learn from our past experiences that it is okay to say, "I do not know" or "I do not understand" in communication. We also learn making a mistake is not the end of the world. This psychological schema enables us to have a comfortable communication. People share a universal fear of rejection. The very thought of being rejected can turn the strongest man or woman into a quivering coward.

\section{Psychological Process Forms Our Psychological Schema}

In communication, we all crave for acceptance. We feel lost if we are not accepted. We feel left out, excluded, and ostracized. We learn about acceptance from infancy. In communication, no matter whether our views are accepted or not, we have our own destiny to create. We can make communication good or bad, successful or not, we are responsible for how it turns out. There may be road bumps during the procedure and not everything will turn out according to our desire and plan. We may have to adjust psychological schema like a road map in our schema of communication. We might come up with a schema B or even a schema C. In the end, we learn how to be assertive. We become aware that being assertive will help us win and get what we want. Sometimes we lose control of communication and we find ourselves stuck in someone else's idea. If we shy away from being accountable and taking charge of our own communication purpose, we will step forward to 
claim for it. It is normal to be a little fearful because it is part of human nature. Our communication needs us make decisions. All decisions have consequences. As we learn to be assertive, we also learn to trust our self when making decisions. Our thoughts influence our world. Our thoughts influence our actions and behavior. So assertiveness is a learned behavior. Unknowingly, we developed certain behavioral patterns that do not support assertiveness. We fall into a trap where we constantly wonder why what we get is not what we wanted.

In communication, we need to learn to assert ourselves by doing things in different ways and produce a different outcome. Our old psychological schema is not always working for us. Those old psychological schema may include features or concepts which have been proved salient or useful in this communication situations. But it may not work in another communication. Generalizing from our past experiences may reduce communicators' uncertainty in communication and thus facilitate them learning another's cultural values and communication styles. The individual psychological identity has to move forward into a societal level of communication relevant to today's globalised milieu.

\section{Conclusion}

Psychological schemas in communication are representing communicators' cultural knowledge. In a communicative process, people psychological schema plays an important role in the success of communication. Not only does the psychological schema guide communicator to respond to other people's cultural perspectives but also it helps them analyze other people's communication goals. Based on people's own judgment, communicators adjust their behavioral patterns that they have learnt in life. People allow themselves to evaluate the cause and effect of their communicative behavior patterns to reach the goal of their communication. Once they are clear about their goal of their communication, they begin to be assertive. Once both communicators see they are already part of the way to a goal their sense of cooperation and confidence increases. Their communication stops drifting along with no plan. Communicators' psychological schema helps them to sustain and follow through their communication goals and lets them be aware of their communication benefits they will enjoy. This helps to sustain more new assertive communication.

\section{References}

Abbe, A. (2008). Building cultural capability for full-spectrum operations (Study Report 2008-04). Arlington, VA: U.S. Army Research Institute for the Behavioral and Social Sciences.

Berg, I. K., \& Steiner, T. (2003). Children's solution work. New York: W.W. Norton and Company.

Ericsson, K. A., \& Lehmann, A. C. (1996). Expert and exceptional performance: Evidence of maximal adaptation to task constraints. Annual Review of Psychology, 47, 273-305.

Freeman, J., Epston, D., \& Lobvits, D. (1997). Playful approaches to serious problems. New York: W.W. Norton and Company.

Nishida, H. (1999). A cognitive approach to intercultural communication based on schema theory. International Journal of Intercultural Relations, 23, 753-777.

Osland, J. S., \& Bird, A. (2000). Beyond sophisticated stereotyping: Cultural sense-making in context. Academy of Management Executive, 14, 65-77.

Roffey, S. (Ed.). (2002). School behaviour and families. London: David Fulton Publishers.

Stein, K. F. (1994). Complexity of the self-schema and responses to disconfirming feedback. Cognitive Therapy and Research, 18, 161-178.

Tse, D., Langston, R. F., Kakeyama, M., Bethus, I., Spooner, P. A., ... Wood, E. R. (2007). Schemas and memory consolidation. Science, 316, 76-82. 